\title{
JUSTIÇA E DIREITOS HUMANOS NA POLÍTICA EDUCACIONAL PORTUGUESA
}

\author{
Carlos Alberto Vilar Estêvão \\ Instituto de Educação e Psicologia da Universidade de Minho, Portugal
}

\section{JUSTIÇA E DIREITOS HUMANOS}

As discussões em torno da justiça e dos direitos humanos têm trilhado um caminho algo tortuoso, havendo autores que preferem defender posições universalistas enquanto outros optam por encarar a justiça $e$ os direitos de um modo contextualizado face às comunidades concretas.

A propósito desta discussão, Rawls (1998: 74), por exemplo, considera que os direitos humanos devem colocar-se numa perspectiva universalista, acrescentando que eles têm como uma das suas funções "fixar os limites da soberania interna do Estado" ao mesmo tempo que salienta que os direitos humanos são parte de "um direito razoável dos povos e fixam limites às instituições domésticas exigidas por esse direito a todos os povos" (ib.). Reafirma que os direitos humanos são uma condição necessária da legitimidade de qualquer regime e da decência da sua ordem jurídica, para além de fixarem um limite ao pluralismo entre os povos. O autor pensa, finalmente, que são os direitos humanos que acabam por civilizar a própria democracia e o Estado.

Outros autores defensores da justiça universal consideram também que as justiças particulares diminuem a dignidade da justiça universal; acentuam as desigualdades; agravam o fanatismo, o paroquialismo; facilitam a submissão às autoridades locais; tornam a justiça do mais forte ainda mais poderosa; espartilham a sociedade em conflitos legítimos; absolutizam as diferenças (não fazendo, por conseguinte, a diferenciação das diferenças); transformam as comunidades políticas em fortalezas, hostis à coexistência com outras culturas; tornam-nos indiferentes face aos problemas planetários; tornam difícil o combate à injustiça cada vez mais global e às ingerências externas; dificultam a emergência da cidadania terrestre.

Contrariando a defesa do carácter universalista dos direitos, Mackinnon (1998: 109) considera que, tal como são concebidos pelos contratualistas liberais, esses direitos resultam tão abstractos que pessoas com crenças diametralmente opostas podem coincidir com eles sem se fazer justiça a ninguém em particular.

No mesmo sentido os multiculturalistas e os defensores do pós-colonialismo defendem a marcação contextualizada dos direitos humanos, até porque se tem verificado que, em nome do pretenso carácter universalista da justiça e dos direitos humanos, se têm forjado justificações para o imperialismo, o colonialismo, o patriarcalismo, o androcentrismo, o capitalismo.

$\mathrm{Na}$ verdade, os pluralistas consideram que a justiça omite os problemas do reconhecimento das diferenças de género, sexuais, religiosas, étnicas, idade, cultura, localidade, afiliação grupal; omite as questões da representação nos órgãos de decisão política dos menos afortunados; despreza as questões da afectividade, as relações de dependência e de interdependência; permite defender valores diametralmente opostos sem se fazer verdadeiramente justiça a ninguém; silencia a emergência de identidades alternativas, desde que não compatíveis com o oficialmente permitido; protege os direitos dos socialmente não direitos ou dos marginais; 
degenera frequentemente numa "luta contra o mal" ou numa moralização das políticas de expansão (imperialismo moral); impõe uma justiça ocidental, colonial, do Norte; só se preocupa com a justiça baseada no sistema político-económico; defende direitos humanos no século XXI mediante um sistema internacional concebido pelos vencedores em 1945; não passa de uma metanarrativa com intuitos universalizadores que a crítica pós-moderna vem desconstruindo.

Independentemente das várias posições, o que parece ser pacífico é que a circunstância primordial da justiça tem a ver com a experiência da injustiça, da negatividade, ou seja, com o reconhecimento de que a sociedade, como diria Rawls, não está bem ordenada. E perante tal facto, não se pode ficar indiferente.

\section{DIREITOS HUMANOS: ENTRE O ESTADO E O MERCADO}

$\mathrm{Na}$ actual conjuntura do capitalismo flexível e transnacional, do "novo espírito do capitalismo", os direitos humanos confrontam-se com sérios desafios que resultam de novas concepções do papel do Estado e do mercado.

Para simplificar, vamos referir-nos apenas a duas tendências que claramente influenciam as concepções e práticas de experienciação dos direitos humanos: a abordagem mercantil e a abordagem igualitária, de acordo com a sugestão de Lukes (1998).

\section{a) Abordagem mercantil}

O Estado actual parece querer remeter-se a mero regulador e avaliador, qual Estado oco, perdendo a sua substância de "educador". Deste modo, parece ter-se tornado num Estado fraco na capacidade de respeitar os direitos, mas forte na regulação e apoio ao mercado (ou à competitividade).

Por outro lado, o Estado actual parece reforçar a substância ideológica do individualismo ao mesmo tempo que apoia a visão "libertária" dos direitos integrados num contexto de liberdade de mercado ${ }^{3}$.

Aqui, o actual mercado, ou o mercado da "nova economia", é visto como a solução final para os problemas contemporâneos, não descurando até a protecção da justiça e dos direitos humanos num sentido que, apesar de tudo, permanece algo paradoxal: por um lado, reconhece-se que é bom que se fale deles até para que os mecanismos de mercado possam funcionar bem e manter uma certa boa consciência; por outro lado, a justiça e os direitos que interessam são sobretudo os de pendor individualista e de conservação da ordem social vigente.

\section{b) Abordagem igualitária}

Uma outra atitude em oposição à mercantil, embora aparentemente menos realista no contexto actual, pode ser analisada a partir de uma perspectiva "igualitária", valorizadora da política como diálogo.

Nesta abordagem, o Estado assume claramente uma atitude interventora do ponto de vista da defesa e promoção dos direitos humanos e da justiça, deixando de lado a posição tantas vezes repetida de colocar a sua justiça acima da justiça. Foca-se o compromisso positivo para a concessão de direitos civis de igual valor a cada um e para a manutenção de níveis mínimos decorosos para todos, dentro de um contexto geral de crescimento e desenvolvimento.

Esta abordagem é importante, porque ela nos permite desconstruir os mecanismos sedutores da racionalidade mercantil e retirar até eventuais vantagens em termos de direitos humanos. 
Explicando melhor: a actual concepção de mercado já não é a de mero mecanismo de alocação de recursos, mas é também uma instituição social inscrita num marco legal e moral, que deve ter presente, para funcionar melhor ou de uma forma mais eficiente, a superioridade dos níveis de consciência social alcançado pela humanidade ou por certas sociedades acerca do que é justo.

Tal como afirma Cortina (2002: 246), "a virtude da justiça, exercida a partir de critérios situados no nível pós-convencional do desenvolvimento moral, é nesta mudança de século condição de possibilidade do eficiente funcionamento do mercado na ordem global."

Este modo de pensar tem a vantagem de repor a questão da ordem moral da justiça no interior da ordem económica do próprio mercado, rejeitando a ideia do mercado ser uma zona franca ou uma offshore do ponto de vista moral. O mercado não é uma actividade meramente económica, abstracta, separada da sociedade. Portanto, ainda que o mercado seja um espaço da liberdade onde reina a desigualdade, tal não significa que seja 'amoral' o que tenha de ficar à margem da justiça.

E então, a educação, ainda que forçada como tem estado a empresarializar-se e a mercantilizar-se, a orientar-se pela ditadura do cliente, venerando os santos e gurus do mercado educativo, também pode jogar aqui um papel importante.

\section{EDUCAÇÃO, JUSTIÇA E DIREITOS HUMANOS}

A educação é um dos lugares naturais de aplicação e expansão dos direitos humanos, embora ela própria tenha vindo, na actual conjuntura do capitalismo flexível e transnacional, a confrontar-se com sérios desafios que resultam de novas concepções do papel do Estado que vão no sentido de este se tornar mais irrelevante nas funções sociais, nomeadamente ao nível da capacidade de respeitar e fazer respeitar os direitos.

Não obstante estas vicissitudes, a educação, ela própria pertencente à segunda geração dos direitos económicos e sociais, não pode ficar indiferente aos valores e à "formação de uma cultura de respeito à dignidade humana mediante a promoção e a vivência dos valores da liberdade, da justiça, da igualdade, da solidariedade da cooperação, da tolerância e da paz" (Benevides, 2003: 309). Consequentemente, uma escola radicalmente mais justa não pode deixar de integrar valências críticas da ideologia de mercado e uma preocupação pela clarificação e educação de valores; ou seja, a educação tem de ser assumida como um outro nome da justiça.

As implicações desta postura não podem deixar de verificar-se a vários níveis:

ao nível das concepções de instituição educativa

$\mathrm{Na}$ verdade, as instituições educativas podem ser compreendidas de vários modos ou segundo várias metáforas, embora nem todas dêem voz aos actores e nem todas defendam o mesmo sentido de justiça e de respeito pelos direitos dos diversos actores educativos.

Assim, a instituição escolar pode ser compreendida predominantemente como "empresa educativa", ou como "escola cidadã", ou como "escola S.A.", entre outras metáforas possíveis (ver Estêvão, 2004), que apontam para valores diferentes que atravessam a substância dos direitos humanos (ver Quadro I). 
Quadro I:

Relação entre mundos, imagens organizacionais e valores

\begin{tabular}{|l|l|l|}
\hline Mundos & Imagens de organização & Valores \\
\hline industrial & empresa educativa & $\begin{array}{l}\text { eficiência e eficácia } \\
\text { utilidade } \\
\text { modernização }\end{array}$ \\
\hline mercantil & escola S.A. ou mercoescola & $\begin{array}{l}\text { individualismo } \\
\text { competição } \\
\text { valor para os accionistas } \\
\text { concorrência }\end{array}$ \\
\hline cívico & escola cidadã & $\begin{array}{l}\text { igualdade } \\
\text { solidariedade } \\
\text { interesse geral }\end{array}$ \\
\hline
\end{tabular}

Cruzando, agora, as imagens de escola com concepções de justiça e de direitos, deparamo-nos com matizes específicos no que diz respeito a estas últimas, como nos ilustra o quadro seguinte (Quadro II).

\section{Quadro II}

Imagens de escola, justiça e direitos humanos

\begin{tabular}{|l|l|l|}
\hline Imagens de organização & Justiça & Direitos humanos \\
\hline Empresa educativa & justiça industrial & $\begin{array}{l}\text { * visão meritocrática } \\
\text { *empresarialização dos direitos }\end{array}$ \\
\hline Escola S.A. ou mercoescola & justiça mercantil & $\begin{array}{l}\text { *visão libertária } \\
\text { *mercantilização dos direitos }\end{array}$ \\
\hline Escola cidadã & justiça social & $\begin{array}{l}\text { *visão igualitária } \\
\text { *cidadanização dos direitos }\end{array}$ \\
\hline
\end{tabular}

É visível, então, que as nossas opções em termos de um modelo de instituição educativa condicionam o modo como nos posicionamos face à justiça e aos direitos dos outros. De modo mais explícito, as nossas opções em termos compreensivos da escola implicam a reformulação da amplitude do direito de cidadania organizacional; a escolha da cidadanização, da empresarialização ou da mercantilização dos direitos; a alteração do sentido da educação para a cidadania; graus de reconhecimento do poder e do direito de participação dos outros actores educativos.

ii)

\section{ao nível dos currículos}

A cultura produtivista ou do rendimento da educação está na moda, em sintonia com o que ocorre noutros contextos onde os profetas e gurus da excelência Nestlé, do êxito do crocodilo sorridente Lacoste, ou da cadeia fast food da MacDonald e seus valores de plástico são vistos com apreço em detrimento das preocupações pela justiça social.

Agora, o que interessa são currículos sem sexo ideológico, omitindo, portanto, o seu carácter socialmente arbitrário e sendo concebidos como essencialmente indiferentes aos dialectos da justiça, à geografia das diferenças. Torna-se, por isso, cada vez mais relevante, o formato da educação/formação/aprendizagem em kits pré-programados uma vez que estes possibilitam transformá-las numa mercadoria transferível para qualquer parte do globo e fugir, assim, à ditadura do mundo educativo tradicional e às noções de uma qualquer "justiça curricular" (Connell 1995, 1997), que pensa o currículo como uma construção histórica da própria igualdade, enquadrada no debate mais radical sobre justiça social e também na estratégia para realizá-la. 
É aqui que a educação inter/multicultural ganha novo sentido, uma vez que ela deve respeitar simultaneamente uma "política da diferença" e a concepção da educação como parte integrante do "movimento para a solidariedade e justiça social" (Stoer \& Cortesão, 1999: 46).

iii) ao nível da gestão das escolas

A grande moda, salvífica, é de que todas as organizações públicas se salvarão se preencherem os requisitos da nova gestão, ou seja, de uma gestão predominantemente orientada por critérios da gestão privada. De facto, o gerencialismo aí está, qual mensageiro da boa nova, com a missão de salvar as organizações e de modo particular, as instituições educativas.

Face a este fenómeno é dfícil aceitar a ideia de que as escolas devem ser pensadas e geridas dando prioridade sobretudo à democracia e à justiça e não tanto ao controlo. Para contrariar este desígnio ou este novo mandato para a escola e para as instituições educativas, temos defendido que a gestão da escola, para almejar uma verdadeira cidadania organizacional, deve praticar i) uma ética da crítica a todas as formas de opressão e de colonização; ii) mas também uma ética da justiça em cujo cerne se situam as questões dos direitos humanos, da justiça, da igualdade; iii) e, além disso, uma ética do cuidado que reforça a dimensão afectiva da justiça, a preocupação e a solicitude pelos outros.

Aliás, falar em ética da justiça e em ética do cuidado é falar de duas formas complementares ou duas faces que completam o ser humano. Ambas são questões públicas, que devem, por isso mesmo, intervir e ampliar a esfera pública para beneficiar quem está em situação de desvantagem. Depois, uma ética do cuidado é fundamentalmente uma ética dos direitos do homem em que cada um tem o dever de fazer com que o outro seja capaz de expressar o melhor de si em termos de justiça, de reconhecer o outro como sujeito da sua própria existência através do reconhecimento do direito do outro a construir-se, por seu turno, como sujeito (Touraine, 1989: 54$)^{6}$.

\section{EDUCAÇÃO E DIREITOS HUMANOS EM PORTUGAL}

Em Portugal, existe um conjunto de medidas legislativas mais ou menos bem intencionadas com implicações ao nível da justiça e direitos humanos, que partem do carácter democrático quer da Constituição (1976) quer da Lei de Bases do Sistema Educativo (1986).

Contudo, a problemática dos direitos humanos aparece encoberta sob outros conceitos em que se adivinha esta preocupação, ou é remetida para o domínio do currículo oculto ${ }^{8}$.

Restringindo-me fundamentalmente à educação formal, é possível isolar alguns valores éticos que a inspiram, independentemente do modo como os direitos humanos são vividos efectivamente na escola.

Se tivermos em conta a Lei de Bases do Sistema Educativo, ela aponta, nos seus princípios gerais, a abertura aos valores da tolerância, da responsabilidade, da liberdade, da autonomia e da solidariedade, o empenho pela transformação e democratização da sociedade e do ensino, a garantia do direito a uma justa e efectiva igualdade de oportunidades no acesso e sucesso escolares, a valorização dos diferentes saberes e culturas, a cooperação internacional e espírito humanista universalista.

Ou seja, embora a Lei de Bases Portuguesa não mencione expressamente a educação para os direitos humanos, não ignora a dimensão ética, democrática e internacional do direito à educação, integrando objectivos 
que passam pelo direito à diferença, pelo direito à paz, pela educação para o desenvolvimento, pelo direito à paz.

Outras medidas, entretanto, merecem ser destacadas aqui: a criação, em 1993, do Projecto de Educação Intercultural inserido no Secretariado Coordenador dos Programas de Educação Multicultural (criado pelo despacho normativo ํㅜ 63/91, de 13/3, e a desenvolver em escolas do ensino básico situadas em zonas de residência de populações pertencentes a minorias étnicas e com elevada percentagem de insucesso escolar), que contempla, nos seus objectivos gerais, o incentivo a uma educação intercultural que permita: desenvolver atitudes de uma maior adaptação à diversidade cultural da sociedade portuguesa; a dinamização da relação entre a escola, as famílias e as comunidades locais; o incremento da igualdade no acesso e usufruto dos benefícios da educação, da cultura e da ciência; a consideração e valorização dos diferentes saberes e culturas.

No mesmo sentido vai a criação do Secretariado Entreculturas (despacho normativo n 5/2001, de 1/2), onde, invocando-se os valores do humanismo universalista e a extensão dos direitos de cidadania a todos os povos, se incentiva: o diálogo intercultural e a valorização da diversidade étnica nas escolas; a promoção de projectos e programas visando os valores da convivência, da tolerância, do diálogo e da solidariedade; a obrigação de propor acções que contribuam para o conhecimento e reconhecimento da diversidade de culturas e o lançamento de concursos subordinados a temas relativos a direitos humanos e aos valores da solidariedade e respeito pela diferença. Aí se diz, ainda, que compete ao Alto-Comissário para a Imigração e Minorias Étnicas, entidade que fica na dependência da Presidência do Conselho de Ministros, colaborar e dinamizar as "políticas activas de combate à exclusão".

Quanto a outras disposições oficiais do ministério da educação com implicações ao nível dos direitos humanos, há a salientar:

- a promulgação da autonomia das escolas (D-L. no 115/98) que deve contribuir para assegurar a igualdade de oportunidades e a correcção das assimetrias, ao mesmo tempo que se defende que a comunidade e outros actores (os alunos) participem sobretudo no órgão de direcção da escola.

- a reorganização curricular do ensino básico (D.-L. n 6/2001), em que a escola se deve assumir como espaço privilegiado da educação para a cidadania, concretizando-se através de um plano que abranja o trabalho a realizar nas diversas disciplinas e áreas do currículo. Também se prevê a criação de novas áreas curriculares não disciplinares de que destaco a formação cívica.

- Outras medidas de pretenso combate à exclusão merecem ser ressaltadas, embora o seu potencial emancipatório possa ser lido de muitas formas, algumas delas pouco congruentes com a própria emancipação.

Assim, podemos destacar: a gratuitidade da escolaridade obrigatória e apoios sócio-educativos e económicos; o apoio psicopedagógico e de orientação escolar e profissional; o apoio e complemento educativos; o apoio pedagógico acrescido; o atendimento aos alunos com necessidades educativas especiais no contexto do ensino regular; os currículos alternativos; a gestão flexível dos currículos; a constituição de territórios educativos de intervenção prioritária; o estatuto do aluno do Ensino não superior onde se diz que aluno tem o direito e o dever de conhecer e respeitar activamente os valores e os princípios fundamentais "inscritos na Constituição da República Portuguesa, na Declaração Universal dos Direitos do Homem, na Convenção Europeia dos Direitos do Homem e na Convenção sobre os Direitos da Criança, enquanto matriz de 
valores e princípios de afirmação da Humanidade"; o cumprimento da escolaridade obrigatória através de um conjunto de medidas de educação e formação; a criação de cursos de educação e formação visando os jovens em risco de abandono escolar ou que entraram precocemente no mercado de trabalho com níveis insuficientes de formação escolar ou sem qualquer qualificação profissional, entre 15 e 18 anos.

Estamos, pois, perante um conjunto de medidas legislativas mais ou menos bem intencionadas. Mas como acontece em muitos países, o Estado Português é um "Estado dual", promulgando medidas legislativas avançadas mas com pouco impacto na vida quotidiana dos cidadãos, situação agravada pela existência de uma sociedade civil pouco activa e interveniente.

Assim, muitas destas iniciativas parecem ter sido pensadas no sentido da igualização de oportunidades educativas e sociais, da maior justiça social, mas o que acontece frequentemente é concretizarem-se no sentido regulatório, acentuando a racionalidade instrumental, a disciplinarização, a normativização, as desigualdades, o "tratamento cirúrgico" das diferenças, a discriminação, a estigmatização.

\section{O SURTO EMPRESARIALIZADOR E PRIVATIZADOR NAS POLÍTICAS EDUCATIVAS NACIONAIS ACTUAIS}

Um último ponto que me interessa focar é o que tem a ver com a actual tendência de empresarialização das políticas sociais e do favorecimento que, pelo menos retoricamente, tem vindo a ser dado ao sector privado em Portugal por parte da actual coligação governativa (de pendor centro direita), no período de 2002 a 2004.

Em primeiro lugar, é de sublinhar que a partir sobretudo dos finais da década de 80, por circunstâncias várias, o princípio regulador da modernização emerge na educação portuguesa, valorizando-se então o modelo empresarial "como eixo de referência privilegiado na regulação da educação" (Correia, 1999: 107). A partir daí, a educação passa a estar numa tensão entre dois pólos: o da democratização e o da modernização, com particular realce para este último, sobretudo do ponto de vista retórico.

A mesma obsessão pela modernização permanece na década de 90, com a governação socialista, partindo-se da ideia de que a "democratização da educação não se alcança apenas pela massificação da frequência dos vários níveis de escolaridade", mas que deve ser desenvolvida tendo presente, também, "o rigor e a qualidade do ensino e das aprendizagens enquanto condições necessárias para o renovar da confiança social na Escola e na educação" (Pacto educativo: 91).

Assim, o vector da modernização é assumido simbolicamente, agora, como elemento salvador e providencial da sociedade portuguesa enquanto que o vector democrático é assumido sobretudo como reparador das diferenças.

Quanto ao estado actual, a modernização das instituições do governo e dos serviços públicos em Portugal parece querer prosseguir em moldes empresarialistas, vinculada simultaneamente à ideia de competir num contexto global instável e em que se torna necessário emagrecer o sector público, combater o declínio económico e, inclusive, inocular no seu interior fórmulas privatizadoras de concorrência.

A modernização prossegue, agora, na base ou através da gerencialização (enquadrada na ideologia da empresarialização), tendo esta, como novidade, o pressuposto da redução da despesa pública e a ideia de que os mercados representam um modo superior de compromisso económico e social. Ou seja, no actual processo de gerencialização, interessa sobretudo a competição entre fornecedores de serviços, o empowerment dos cidadãos, a ambição das organizações, a focalização nos resultados, a consideração dos cidadãos como 
clientes e a substituição dos mecanismos burocrático pelos mecanismos de mercado no fornecimento de serviços públicos. Tudo isto, em nome da maior produtividade, do sucesso económico e até da maior justiça nomeadamente pelo combate à exclusão e à pobreza.

Não surpreende, pois, que também na educação portuguesa estejamos a assistir a novas formas de controlo e a novas redistribuições das formas de exercer o poder, emergindo neste contexto, como figura paradigmática, o gestor, o qual, mais do que apresentar-se como administrador ou como político, ele tende a ser visto como animador de uma dinâmica de mudança económica e social, baseada no cálculo dos riscos, da eficiência e da performance. Ele torna-se, por isso, importante para captar recursos e financiamentos, para a valorização dos recursos humanos, para a sobrevivência e viabilização económica da organização.

Este pendor empresarializado e gerencialista pode ser visto na proposta de Lei de Bases de Educação da actual coligação governativa de centro direita, quer na acentuação das funções mais estratégicas dos departamentos governamentais responsáveis pelas políticas educativas, quer na aposta na aquisição de novas competências relacionadas com a utilização da informação para a nova sociedade do conhecimento, quer no novo modo de ver a intervenção do ensino privado, quer, ainda, em medidas mais concretas relacionadas com a forma organizacional dos agrupamentos verticais ou com a nova fórmula de gerir as escolas.

Relativamente a este último aspecto, os órgãos executivos da escola têm vindo a merecer uma atenção especial porque neles "reside o papel essencial de modernização e qualificação do sistema educativo", propondo-se, então, a profissionalização da gestão das escolas, com o reforço dos poderes do director da escola, provavelmente no sentido de transformar os burocratas em gestores, inoculando-lhes consciência gerencial.

No que concerne ao ensino privado, o que é possível dizer neste momento é que há mais condições para que as fronteiras entre público e privado se alterem em nome da nova ordem regulatória, mais competitiva e transformacional. Neste sentido, é razoável pensar-se que o actual estado de coisas entre o ensino público estatal e o ensino privado possa vir a alterar-se, de acordo, aliás, com o programa da actual coligação governativa que pretendia:

inverter a situação a que o País foi conduzido implica, como pressuposto essencial, contrariar o crescente estatismo a que está sujeita a educação em Portugal. O quase monopólio da escola pública que hoje existe, em todos os níveis de ensino, não é o modelo desejável. Não por ser pública, mas pelo facto de há muito estar sujeita a limitações no seu funcionamento e na sua cultura, que contrariam o princípio constitucional da liberdade de ensinar e aprender, de escolher e de aceder a um bem que toda a população portuguesa sustenta. Um maior equilíbrio entre as organizações pública, social e privada, enquanto destinatárias das políticas educativas e do esforço de financiamento, é um objectivo que importa alcançar.

Também as declarações públicas dos responsáveis pela educação tendem precisamente a "desvalorizar a imagem da escola igualitária", ao mesmo tempo que sustentam a inconsistência da "velha oposição entre escola pública e escola privada", que não tem, por isso mesmo, qualquer sentido.

Para além dos discursos, que apontam, como este último, para a desinstrumentalização ideológica, também a proposta governamental da nova Lei de Bases de Educação parece agradar em alguns aspectos ao sector privado, desde logo porque ela sublinha uma noção de serviço público de educação independente da titularidade estatal ou não estatal da escola. Reafirma-se o valor do ensino particular e cooperativo como "uma expressão concreta da liberdade de aprender e ensinar", estando ainda previsto o apoio financeiro do Estado, 
mediante contrato, para além de outros apoios nas vertentes pedagógica e técnica, o que, a acontecer, nos remeterá, mais uma vez, para a providenciação pública do privado. Considera-se, finalmente, que a rede de estabelecimentos de serviço público de educação e de ensino, destinada a cobrir as necessidades de toda a população, possa, numa perspectiva de racionalização de recursos e de promoção da qualidade da educação, ser constituída, não apenas por escolas do Estado, mas também por escolas particulares e cooperativas, situação que pode representar mais um passo para a privatização da oferta educativa.

Independentemente do impacto concreto que estas medidas possam vir a ter na revalorização (não apenas simbólica) do privado e no modo como este possa vir a cumprir as suas funções, a dimensão dos direitos terá de estar presente, sobretudo quando o processo actual parece tender a valorizar os direitos de consumidor em detrimento dos direitos de cidadão.

\section{CONCLUSÃO}

Perante os desafios descritos, a formação dos educadores não pode, de maneira nenhuma, ser pensada independentemente do modo como vemos a escola e os direitos.

Numa concepção de escola cidadã, aqui defendida, parte-se de referenciais críticos e democráticos que exigem de qualquer actor educativo a obrigação de propor princípios democráticos e escolas justas, respeitando a ideia de que a "democracia e justiça são mais importantes que a gestão e o controlo" (Ward, 1994: 24).

Esta escola cidadã integra ou pressupõe, no nosso entender, a compreensão das escolas como "esferas públicas democráticas" (Giroux, 1993), em que o pedagógico seja mais político e a aprendizagem se una à própria natureza da mudança social, em que o educador se torne um intelectual público e um verdadeiro agente social.

Agora, a formação deve contemplar as dimensões da ética da crítica e da ética da justiça mas também da ética do cuidado, que mobiliza a emoção e o desejo, a solicitude e a esperança, aspectos estes que entroncam numa visão de um profissional intermulticultural, de um educador cidadão. Só preparados deste modo é que os educadores não faltarão ao respeito dos jovens e crianças, evitando o perigo para que Santos Guerra (2003: 151) alerta, quando escreve que um educador "mal preparado, queimado e sem ilusões é como um lançador de facas com a doença de Parkinson".

\section{BIBLIOGRAFIA}

BeNAVIDES, M. V. (2003). Educação em direitos humanos: de que se trata?. In Raquel L. BARBOSA (org.), Formação de Educadores. Desafios e Perspectivas. S. Paulo: UNESP., pp. 309-318.

CONNELL, Robert W. (1997). Escuelas y Justicia Social. Madrid: Morata.

CoRrEIA, J. A. (1999). As ideologias educativas em Portugal nos últimos 25 anos. Revista Portuguesa de Educação, 12 (1), pp. 81-110.

CORTINA, A. (2002). Justicia y mercado. In J. RUBIO-CARRACEDO, J. M. ROSALES \& M. TOSCANO MÉNDEZ (eds), Retos Pendientes en Ética y Política. Madrid: Trotta, pp. 237-247.

ESTÊVÃO, C. V. (2004). Educação, Justiça e Democracia. S. Paulo: Editora Cortez.

GIROUX, H. (1993). La Escuela y la Lucha por la Ciudadanía. Madrid: Siglo Veintuno Editores. 
LUKES, S. (1998). Cinco Fábulas sobre los derechos humanos. In S. SHUTE \& S. HURTLEY. De los Direchos Humanos, Madrid: Trotta, pp. 29-46.

MACKINNON (1998). Crímenes de guerra, crímenes de paz. In S. SHUTE \& S. HURTLEY. De los Derechos Humanos, Madrid: Trotta, pp. 87-115.

RAWLS, J.(1998). El derecho de gentes. In S. SHUTE \& S. HURTLEY. De los Derechos Humanos, Madrid: Trotta, pp. 47-85.

SANTOS GuerRA, M. (2003). No Coração da Escola. Porto: Asa Editores.

StOen, S. \& CORTESÃO, L. (1999). "Levantando a Pedra". Da Pedagogia Inter/Multicultural às Políticas Educativas numa Época de Transnacionalização. Porto: Afrontamento.

TOURAINE, A. (1989). A travers la reconnaissance de l'Autre. In Commission Nationale Consultive des Droits de I'Homme. Les Droits de l'Homme en Questions. Paris: La documentation française, pp. 47-54.

WARD, J. G. (1994). "Reconciling educational administration and democracy: The case for justice in schools". In N. A. PRESTINE \& P. W. THURSTON (eds.), Advances in Educational Administration, vol. 3, London: JAI Press Inc., pp. 1-27. 


\title{
Contactar
}

Revista lberoamericana de Educación

\author{
Principal OEI
}

